Check for updates

Cite this: Mater. Adv., 2020 1,1980

Received 22nd May 2020

Accepted 11th August 2020

DOI: 10.1039/d0ma00339e

rsc.li/materials-advances

\section{Intrinsic MRI contrast from amino acid-based paramagnetic ionic liquids $\dagger$}

\author{
Praveen Singh Gehlot, (D) ${ }^{\text {ab }}$ Hariom Gupta, (D) *ac Mangal Singh Rathore, ${ }^{a}$ \\ Kusum Khatri ${ }^{a}$ and Arvind Kumar (D)*a
}

\begin{abstract}
Paramagnetic ionic liquids (PMILs) comprising of natural amino acids and tetrachloroferrate(III) as constituent ions were prepared that act as highly efficient dual mode $\left(T_{1}\right.$ and $\left.T_{2}\right)$ responsive contrast agents for magnetic resonance imaging (MRI). The PMILs were characterized by ultraviolet-visible (UV), Raman and EPR spectroscopies, differential scanning calorimetry (DSC), thermogravimetric analysis (TGA), and inductively couple plasma mass spectrometry (ICP MS). DNA stability in the presence of the PMILs was investigated using fluorescence spectrophotometry, circular dichroism (CD), zeta potential analysis, and gel electrophoresis. The behavior of synthesized PMILs as contrast agents was determined and compared with commercially available contrast agents using the rate of relaxivity. The PMILs synthesized herein are environmentally friendly, biodegradable, cost effective, easy to synthesize, stable at cell physiological pH (7.4), non-hazardous to animal DNA, and hence hold promise for future clinical use.
\end{abstract}

\section{Introduction}

In medical science, identification of a target area is essential for the diagnosis of many diseases. Cells or lesions to be targeted can be visualized by using a tracking or sensing agent. For example, $\mathrm{BaSO}_{4}$ is used to enhance the contrast of a radiograph by opacifying parts of the gastrointestinal tract on an X-ray film so that a specific area can be more easily targeted. Magnetic resonance imaging (MRI) is also a well-known non-invasive technique for imaging affected tissue in various diseases, and principally, it is similar to the nuclear magnetic resonance (NMR) technique. In contrast with NMR, an MRI image is produced by spatially encoding the NMR signal generated from the proton relaxation of the object under the applied magnetic field. ${ }^{1}$ For clinical use, two types of MRI contrast agents have been synthesized: (1) dextran-coated superparamagnetic iron oxide nanoparticles (SPIONs), which generate darker images $\left(T_{2}\right.$ MRI negative contrast agents) and (2) $\mathrm{Gd}(\mathrm{III})$-chelate-based complexes that generate brighter images ( $T_{1}$ MRI positive contrast agents). ${ }^{2}$

\footnotetext{
${ }^{a}$ Academy of Scientific and Innovative Research (AcSIR), Ghaziabad-201002, India CSIR-Central Salt and Marine Chemicals Research Institute, Council of Scientific and Industrial Research, G. B. Marg, Bhavnagar, 364002, Gujarat, India.

E-mail: mailme_arvind@yahoo.com, arvind@csmcri.res.in; Fax: +91-278-2567562; Tel: $+91-278-2567039$

${ }^{b}$ Department of Chemistry, Government Science College, Pardi, Valsad-396125, Gujarat, India

${ }^{c}$ Analytical Chemistry Division, CSIR-Central Institute of Medicinal and Aromatic Plants (CSIR-CIMAP), Lucknow, India

$\dagger$ Electronic supplementary information (ESI) available. See DOI: 10.1039/ d0ma00339e
}

For new contrast agents to be superior, they must overcome the poor resolution of the presently reported contrast agents, which may be due to weak contrast, low sensitivity, low intensity of the image, diagnostic time limitations, or a short signal for long-term in vivo measurements. Although researchers have reported and reviewed numerous contrast agents, only nanoparticles and chelate-based contrast agents have been approved by the US FDA (Food and Drug Administration). ${ }^{3,4}$ There are disadvantages to these contrast agents, such as low relaxation value, metal leaching problems, side effects that create severe diseases, nanoparticles that have the ability to interact with cells, and same-sized molecule-like proteins or enzymes that can distribute in cell plasma according to their surface charges. ${ }^{5}$ Dual $T_{1}$ and $T_{2}$ responses have been found in coated nanoparticles ${ }^{6}$ and hybrid lanthanide oxide nanoparticles. ${ }^{2,7}$

A Fe-based targeted contrast agent for cancer cells was recently patented, where Fe nanoparticles become captured by a larger complex ligand. ${ }^{8}$ In the present work, we synthesized iron-containing amino acid-based paramagnetic ionic liquids as alternative contrast agents to overcome the toxic and harmful side effects of contrast agents prepared from metallic solid nanoparticles using metal-ligand chemistry. It is well known that ionic liquids are considered as comparatively green chemicals and can be modified at the molecular level to achieve task-specific applications. With the reaction of 1-butyl-3methylimidazolium chloride $\left(\left[\mathrm{C}_{4} \mathrm{mim}\right][\mathrm{Cl}]\right)$ with ferric chloride $\left(\mathrm{FeCl}_{3}\right)$, paramagnetic ionic liquids (PMILs) were synthesized for the first time by Satoshi and Hamaguchi et al. ${ }^{9}$ Many d- and f-block transition metal-based PMILs have subsequently been synthesized and used for numerous applications, including 
mapping and imaging of porous subterranean formation, ${ }^{10}$ and magnetic levitation of diamagnetic materials. ${ }^{11}$ Some PMILs have been explored for desulfurization, ${ }^{12}$ organic synthesis, ${ }^{13}$ micro extraction, ${ }^{14-16}$ electrocatalysis, ${ }^{17}$ probes for vesicles, ${ }^{18}$ selfassembling media for surfactants, ${ }^{19}$ acidic catalysis, ${ }^{20}$ density measurement, ${ }^{21}$ paramagnetic polymer synthesis, ${ }^{22,23}$ microemulsion formulation, ${ }^{24}$ chitosan-supported magnetic IL-based catalysis, ${ }^{25} \mathrm{CO}_{2}$ separation, ${ }^{26}$ analytical applications, ${ }^{27,28}$ and other diverse applications. ${ }^{29-31}$ Brown et al. studied paramagnetic surfactants (magnetic surfactants) with symmetric $\left[\mathrm{FeCl}_{4}\right]^{-}$and asymmetric anions $\left[\mathrm{FeCl}_{3} \mathrm{Br}\right]^{-32}$ PMILs also have been considered for biological applications, for example, with genomic DNA to observe their interaction in the fields of pharmacokinetics and biotechnology and gain a deeper understanding of DNA preservation and stability, ${ }^{33}$ extraction of DNA, ${ }^{34}$ and drug delivery system. ${ }^{35}$

In continuation of such interesting applications, Daniel et al. revealed the utility of $\left[\mathrm{FeCl}_{4}\right]^{-}$in a ${ }^{1} \mathrm{H}$ NMR relaxation study, where they had measured magnetic relaxation in a mixture of $\left[\mathrm{P}_{66614}\right][\mathrm{Cl}]$ ionic liquid and mixtures of $\left[\mathrm{P}_{66614}\right]\left[\mathrm{FeCl}_{4}\right]$ with dimethyl sulfoxide (DMSO). ${ }^{36}$ In one of our previous reports, PMILs as surfactants were prepared, and were studied with DNA for use as MRI contrast agents. ${ }^{37}$ However, due to their amphiphilic nature, DNA compaction resulted.

Herein, non-amphiphilic amino acid-based PMILs were specifically prepared for use in MRI analysis (Table 1). ${ }^{38}$ These non-amphiphilic amino acid-based PMILs exhibit a strong dual response ( $T_{1}$ and $T_{2}$ relaxation) in MRI that is rarely found in other complex molecules or hybrid metallic nanomaterials. ${ }^{2,6,39}$ PMILs have unique advantages over commercially available contrast agents with respect to the adverse effects that toxic metal ions such as Gd have on cell functionality, ${ }^{40}$ and damaging effects on cells and their physiology from metallic nanoparticles. ${ }^{5,41,42}$ PMILs are cost-effective and can be synthesized using a facile process. The physical interactions between PMILs and DNA were studied to reveal the optimum concentration range of PMILs in which DNA remains stable.

\section{Experimental section}

\subsection{Materials}

The amino acids glutamic acid, proline, alanine, and valine with $>98 \%$ purity were purchased from TCI Chemical (India) Pvt. Ltd Ferric chloride hexahydrate ( $97 \%$ purity), ethidium bromide, Trizma base (99.9\% purity), and sodium salt of deoxyribonucleic acid (DNA) from salmon testes were purchased as analytical reagent (AR) grade chemicals from Sigma-Aldrich. Methanol solvent and thionyl chloride of AR grade were procured from SD-Fine Chemicals Ltd, India. All chemicals were AR grade and used as received. Millipore grade water with specific conductivity of $3 \mu \mathrm{S} \mathrm{cm}^{-1}$ and surface tension of $71 \mathrm{mN} \mathrm{m}^{-1}$ was used for the solution preparation.

\subsection{Synthesis of PMILs}

Two methods were used for the synthesis of PMILs: (1) without esterification of amino acids, and (2) with esterification of amino acids (Scheme 1).
Table 1 Name of amino acid, code, and structure of PMILs used for studies

\begin{tabular}{ll}
\hline $\mathrm{AACOOR}]\left[\mathrm{FeCl}_{4}\right]$ & Code used \\
$\mathrm{AA}=$ proline, $\mathrm{R}=\mathrm{H}$ & $\left.\mathrm{Pro}_{\mathrm{FeCl}}\right]$ \\
$\mathrm{AA}=$ glutamic acid, $\mathrm{R}=\mathrm{H}$ & $\mathrm{Glu}\left[\mathrm{FeCl}_{4}\right]$ \\
$\mathrm{AA}=$ glutamic acid, $\mathrm{R}=\mathrm{CH}_{3}$ & $\mathrm{GluC}_{1}\left[\mathrm{FeCl}_{4}\right]$
\end{tabular}

Synthesis of PMILs from amino acids without esterification. For the synthesis of PMILs without esterification, an equimolar ratio of amino acid hydrochloride $(5 \mathrm{~g})$, which was prepared by protonation at lower $\mathrm{pH}$, was mixed with ferric chloride hexahydrate in $100 \mathrm{~mL}$ ethanol. The reaction mixture was stirred at room temperature for 1 to 2 days until the completion of the reaction (Fig. 1). This procedure can also be extended to other biological and drug molecules containing the $\mathrm{NH}_{2}$ group with the possibility of formation of quaternized cation or alkyl chain containing heterocyclic (nitrogen containing) cations with tetrahaloferrates, such as $\left[\mathrm{FeCl}_{3} \mathrm{Br}\right]^{-},\left[\mathrm{FeCl}_{3} \mathrm{I}\right]^{-}$, or other tetrahalo transition metals for paramagnetic moieties.

Synthesis of PMILs from amino acids with esterification. Methyl ester of amino acids was synthesized according to a reported procedure. ${ }^{43,44}$ The reaction of the amino acid (5 g) with thionyl chloride (in a 1:1.2 molar ratio) in $150 \mathrm{~mL}$ of methanol solvent was carried out and refluxed for more than one day. Progress of the reaction was monitored using ninhydrin spray. After completion of the reaction, the solvent was removed under reduced pressure, and the methyl ester of amino acid hydrochloride was stored in a desiccator, followed by a diethyl ether wash. These methyl esters of amino acid hydrochloride $(5 \mathrm{~g})$ were further reacted with ferric chloride hexahydrate in an equimolar ratio (1:1 mole eq.) in $100 \mathrm{~mL}$ of ethanol solvent. The reaction mixture was stirred at room temperature until completion of the reaction. The product was washed with a small amount of water to remove unreacted

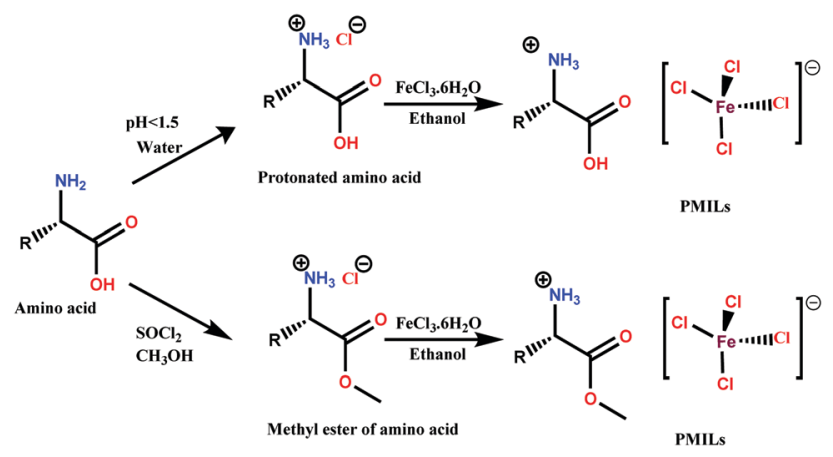

Scheme 1 Reaction scheme. 

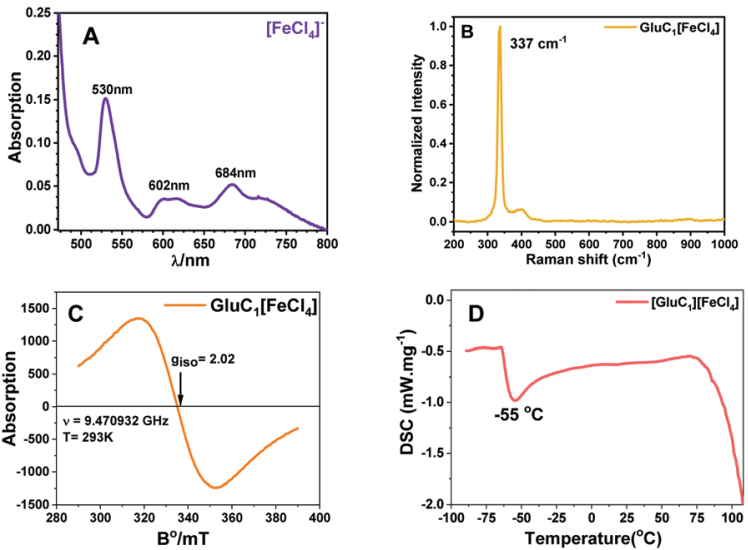

Fig. 1 Profiles of a representative PMIL, $\left(\mathrm{GluC}_{1}\left[\mathrm{FeCl}_{4}\right]\right)$. (A) UV spectrum of $\left[\mathrm{FeCl}_{4}\right]^{-}$anion, (B) Raman spectrum, (C) EPR spectrum and (D) DSC trace.

ferric chloride. Products were completely dried and stored in a vacuum desiccator to ensure that moisture would not affect the results.

The synthesized PMILs were characterized by CHN microanalysis, mass spectrometry (MS), NMR, and inductively couple plasma mass spectrometry (ICP MS). All characterization data are given in the $\mathrm{ESI}^{\dagger}$ (Table S1 and Fig. S1). The elemental percentage of Fe in PMILs is given in Table S2 (ESI $\dagger$ ).

\subsection{Methods}

DNA solution preparation. A DNA stock solution was prepared by adding an appropriate amount of DNA to $50 \mathrm{~mL}$ of $80 \mathrm{mmol} \mathrm{L}^{-1}$ Trizma base-EDTA-hydrochloride (TE.HCl) buffer solution and dissolving overnight for complete solubilisation. The actual concentration of DNA was determined using a NanoDrop $^{\circledR}$ ND-1000 spectrophotometer. The DNA solution was prepared in buffer at physiological $\mathrm{pH} 7.4$, and the concentration of DNA was maintained at the limit of $92 \pm 2 \mathrm{ng} \mu \mathrm{L}^{-1}$. The absence of any protein impurities was confirmed using a NanoDrop ${ }^{\circledR}$ ND-1000 spectrophotometer each time. The $A_{260} /$ $A_{280}$ value was nearly 1.88 , which indicated the absence of any protein impurities.

Ultraviolet-Visible (UV-Vis) Raman and electron paramagnetic resonance (EPR) spectroscopy measurements. The presence of $\left[\mathrm{FeCl}_{4}\right]^{-}$as a constituent of synthesized PMILs was verified by using a Shimadzu UV-2700 UV-Vis spectrophotometer and LabRAM HR Evolution Horiba Jobin Yvon Raman spectrometer (quartz cuvette with $1 \mathrm{~cm}$ path length) at 298.15 K. For measurement, samples were prepared in acetonitrile or methanol solvent. The paramagnetic property of anion $\left[\mathrm{FeCl}_{4}\right]^{-}$was ensured by the EPR spectrum using mt-MiniScope MS5000 ESRStudio by Freiberg Instruments at $298.15 \mathrm{~K}$.

Thermal characterization. The thermal properties of PMILs were investigated using a NETZSCH DSC 204F1 Phonex 240-120239-L instrument with a scan rate of $10{ }^{\circ} \mathrm{C} \mathrm{min}^{-1}$ and NETZSCH TG 209 F1 Libra TGA 209F1D-0105-L instrument with a scan rate of $10{ }^{\circ} \mathrm{C} \mathrm{min}^{-1}$ from 30 to $600{ }^{\circ} \mathrm{C}$.
Far-UV circular dichroism spectroscopy. The far-UV circular dichroism (CD) spectra of DNA in TE. $\mathrm{HCl}$ buffer at $\mathrm{pH} 7.4$ were recorded in triple measurements at the wavelength range of 200-400 nm using a Jasco J-815 CD spectrometer under an $\mathrm{N}_{2}$ environment at a temperature of $298.15 \mathrm{~K}$. Experiments were carried out in a quartz cuvette with a path length of $1 \mathrm{~mm}$. The spectra were collected at a scan rate of $100 \mathrm{~nm} \min ^{-1}$. The response time and the bandwidth were $2 \mathrm{~s}$ and $0.2 \mathrm{~nm}$, respectively. The secondary structure of procured DNA was confirmed from the CD spectra (Fig. S5, ESI $\dagger$ ), which determined the presence of the B-form of dextrorotatory fully hydrated double helical DNA. The uncertainty in band position, which was calculated through standard deviation in each measurement, was found to be $\pm 0.1 \mathrm{~nm}$.

Ethidium bromide exclusion assay. According to a previous report, ${ }^{45}$ a $50 \mu \mathrm{L}$ solution of $0.1 \mathrm{mM}$ ethidium bromide (EB) was mixed with $2 \mathrm{~mL}$ of buffer, and the fluorescence spectra of water-EB were recorded in the absence of DNA and in the presence of DNA within the range of 500 to $700 \mathrm{~nm}$ at an excitation wavelength $\left(\lambda_{\mathrm{ex}}\right)$ of $530 \mathrm{~nm}$ using a Fluorolog Horiba Jobin Yvon fluorescence spectrophotometer. The PMIL solution was successively added up to an Fe concentration of $10 \mathrm{mM}$ in a $2 \mathrm{~mL}$ cuvette containing EB-DNA complex, and triple measurements of the spectra were recorded at $298.15 \mathrm{~K}$.

Determination of zeta potential $(\zeta)$. The negative surface charge of DNA in the presence of PMILs was measured in terms of zeta potential $(\zeta)$ using a Zetasizer Nano ZS light-scattering apparatus (Malvern Instruments, UK) with a He-Ne laser $(633 \mathrm{~nm}, 100 \mathrm{~mW})$ at $298.15 \mathrm{~K}$. For measurements, the solution was transferred through a $0.25 \mu \mathrm{m}$ membrane filter into a DTS 1060 cell possessing a gold-coated electrode. The Smoluchowski approximation was selected during measurements.

Isothermal titration calorimetry (ITC). Enthalpy changes $(\mathrm{dH})$ due to dilution and the interaction of DNA in successive injections of PMILs in buffer solution were measured using a MicroCal ITC200 microcalorimeter, with an instrumentcontrolled $40 \mu \mathrm{L}$ Hamilton syringe. Next, $2 \mu \mathrm{L}$ aliquots of stock solution were added with continuous stirring (at $500 \mathrm{rpm}$ ) to a sample cell containing $200 \mu \mathrm{L}$ of buffer or DNA solution. Parameters such as temperature, time of addition, and duration between each addition were controlled by automated software. The subtracted enthalpogram is presented to remove the enthalpy of dilution.

Agarose gel electrophoresis. To confirm DNA degradation, $2 \mu \mathrm{L}$ loading dye for tracking the path $(0.25 \% \mathrm{w} / \mathrm{v}$ bromophenol blue, $0.25 \% \mathrm{w} / \mathrm{v}$ xylene cyanol $\mathrm{FF}$, and $30 \%$ glycerol in water) was mixed with $5 \mu \mathrm{L}$ PMIL-DNA solution, and these mixtures were loaded into wells of an agarose gel. Electrophoresis using a BGPS 300/400 power supply was then carried out for $60 \mathrm{~min}$ at $50 \mathrm{~V}$ in Trizma base-boric acid-EDTA (TBE) buffer at $\mathrm{pH}$ 8.3 after $3 \mathrm{~h}$ incubation at room temperature. The DNA bands were visualized, and images were obtained using the molecular imager Gel Doc ${ }^{\mathrm{TM}} \mathrm{XR}^{+}$with ImageLab ${ }^{\mathrm{TM}}$ software by Bio-Rad.

${ }^{1}$ H-NMR and magnetic resonance imaging. The methyl esters of proline, glutamic acid, valine, and alanine were characterized via ${ }^{1} \mathrm{H}$ NMR using a BRÜKER AVANCE $500 \mathrm{MHz}$ instrument with 
samples dissolved in methanol- $\mathrm{d}_{6}$ solvent. In vitro MRI and relaxation rate experiments were carried out according to an earlier report. ${ }^{46}$ Magnetic resonance images and relaxometric contrasting characteristics of PMILs and Gd-BOPTA were acquired with a BRÜKER AVANCE $500 \mathrm{MHz}(11.7 \mathrm{~T})$ NMR instrument using a micro-imaging probe and Paravision imaging software. $T_{1}$ and $T_{2}$ weighted MRI images of aqueous phantoms of each PMIL having different concentrations (0.3, $0.5,0.7$, and $1.0 \mathrm{mM}$ Fe concentration) measured in terms of Fe concentration were acquired using spin-echo pulse sequences (RAREVTR and MSME) with acquisition parameters FOV = $0.4 \mathrm{~cm}, \mathrm{TR}=350 \mathrm{~ms}, \mathrm{TE}=8 \mathrm{~ms}, 128 \times 128$ matrix and $\mathrm{FOV}=$ $0.4 \mathrm{~cm}, \mathrm{TR}=2000 \mathrm{~ms}, \mathrm{TE}=36,128 \times 128$ matrix respectively for PMSAILs, and FOV $=0.5 \mathrm{~cm}, \mathrm{TR}=250 \mathrm{~ms}, \mathrm{TE}=8 \mathrm{~ms}, 128 \times 128$ matrix and $\mathrm{FOV}=0.5 \mathrm{~cm}, \mathrm{TR}=2000 \mathrm{~ms}, \mathrm{TE}=72,128 \times 128$ matrix respectively for Gd-BOPTA. $T_{1}$ and $T_{2}$ relaxation times of aqueous phantoms with different concentrations of PMILs $(0.3,0.5,0.7$, and $1.0 \mathrm{mM} \mathrm{Fe})$ and Gd-BOPTA $(0.3,0.5,0.7$, and $1.0 \mathrm{mM} \mathrm{Gd}$ ) were measured using a Bruker RAREVTR (FOV = 0.4 or $0.5 \mathrm{~cm}, \mathrm{TE}=8 \mathrm{~ms}, \mathrm{TR}=250$ to $2850 \mathrm{~ms}$, and $128 \times$ 128 matrix) and MSME (FOV $=0.4$ or $0.5 \mathrm{~cm}, \mathrm{TE}=12$ to $72 \mathrm{~ms}$, $\mathrm{TR}=2000 \mathrm{~ms}$, and $128 \times 128$ matrix) MRI pulse sequences, respectively. $T_{1}$ and $T_{2}$ relaxivity values were calculated through eqn (1) by linear curve fitting of the relaxation rate $\left(1 / T_{1}\right.$ and $1 / T_{2}$ ) versus metal concentration using Paravision software.

\section{Results and discussion}

\subsection{Structural and thermal characterization of PMILs}

In PMILs, the anion $\left[\mathrm{FeCl}_{4}\right]^{-}$is the component responsible for the paramagnetic properties of the system due to the involvement of a high spin with five unpaired electrons. The structure of paramagnetic anion was characterized using UV-Vis and Raman spectroscopies. The UV-Vis spectra of the anion $\left(\left[\mathrm{FeCl}_{4}\right]^{-}\right)$, which is common for all of the PMILs, is given in Fig. 1(A). In Fig. 1(A), the characteristic band has appeared between the ranges of 450 to $700 \mathrm{~nm}$. The peak appearing at $529 \mathrm{~nm}$ can be assigned to the ${ }^{6} \mathrm{~A}_{1} \rightarrow{ }^{4} \mathrm{~T}_{2}$ (a) transition, the peak at $602 \mathrm{~nm}$ to the ${ }^{6} \mathrm{~A}_{1} \rightarrow{ }^{4} \mathrm{~A}_{2}$ transition, and the peak at $684 \mathrm{~nm}$ to the ${ }^{6} \mathrm{~A}_{1} \rightarrow{ }^{4} \mathrm{~T}_{2}$ (b) transition in $\mathrm{Fe}$ (III) ion in a tetrahedral environment. ${ }^{47}$

These characteristic absorption bands confirm the existence of the $\left[\mathrm{FeCl}_{4}\right]^{-}$anion, and are similar for all other PMILs. For further verification of the anion structure, Raman spectra of $\left[\mathrm{FeCl}_{4}\right]^{-}$were recorded, and a representative Raman spectrum of $\left(\mathrm{GluC}_{1}\left[\mathrm{FeCl}_{4}\right]\right)$ is given in Fig. 1(B). The Raman spectra of other PMILs are provided in the ESI $\dagger$ (Fig. S2). The characteristic single band appearing near $334 \mathrm{~cm}^{-1}$ is due to the vibration of the $\mathrm{Fe}-\mathrm{Cl}$ bond in tetrahedral $\left[\mathrm{FeCl}_{4}\right]^{-}$anion. This $334 \mathrm{~cm}^{-1}$ value belongs to the total symmetric vibration $\mathrm{A}_{1}$ mode that is similar to previously reported tetrachloroferrate(III)like anion. ${ }^{12,48}$ The EPR spectrum of the $\left[\mathrm{FeCl}_{4}\right]^{-}$constituent recorded at room temperature in solution phase indicated a single isotropic EPR line that is characteristic only of an unresolved ${ }^{6} \mathrm{~S}_{1}$ state. The EPR spectrum of the $\mathrm{Fe}^{3+}$ ion strongly depends on its environment in the tetrahedral crystal field. ${ }^{49} \mathrm{~A}$ high-quality, intensive signal from a symmetric anionic form of $\left[\mathrm{FeCl}_{4}\right]^{-}$is seen in the EPR spectra in Fig. 1(C) and Fig. S3 (ESI $\dagger$ ).

All these techniques collectively validate and confirm the paramagnetic nature and tetrahedral structure of $\left[\mathrm{FeCl}_{4}\right]^{-}$ anion $\left(T_{\mathrm{d}}\right)$. Fig. $1(\mathrm{D})$ shows a DSC trace of $\mathrm{GluC}_{1}\left[\mathrm{FeCl}_{4}\right]$. The DCS thermogram of all PMILs show the glass transition temperature $\left(T_{\mathrm{g}}\right)$ below $100{ }^{\circ} \mathrm{C}$, which satisfies the criteria for ionic liquids. ${ }^{44}$ The degradation temperature $\left(T_{\mathrm{d}}\right)$ was measured from thermogravimetric analysis (TGA). The first change at the initial state indicates the removal of water molecules between 100 to $120{ }^{\circ} \mathrm{C}$. After that, a large change was observed due to a loss of mass along with the temperature increase. ${ }^{50}$ The removal of water molecules indicates its water binding affinity, which enables high solubility in water. TGA and DSC traces for other PMILs are provided in Fig. S4 (ESI $\dagger$ ). The experimental values of DSC and TGA for PMILs are given in Table S2 (ESI $\dagger$ ).

\subsection{DNA-PMIL interactions}

CD spectroscopy. The structural stability of DNA in the presence of PMILs was determined using circular dichroism (CD) spectroscopy. The CD spectra of animal DNA with various concentrations of PMILs were recorded, and the results are displayed in Fig. 2(A). The spectrum of native pure DNA in buffer solution indicates a positive maxima at approximately $276 \mathrm{~nm}$ and a negative minima near $245 \mathrm{~nm}$, with a crossover point situated nearby at $258 \mathrm{~nm}$. These values suggest that the used pure DNA is the fully hydrated double helix B form and dextrorotatory in nature. ${ }^{51}$ The secondary structure of B-DNA remained unchanged within the concentration range $(0.1$ to $5 \mathrm{mmol} \mathrm{L}^{-1} \mathrm{Fe}$ ), which is the further acceptable range for MRI investigations. At higher concentrations $\left(>3 \mathrm{mmol} \mathrm{L}^{-1} \mathrm{Fe}\right)$, the PMIL began to interact with B-DNA, and bands underwent distortion. At low concentration of $\mathrm{Fe}$ in PMILs, peaks of B-DNA did not greatly shift, and all the peaks in the CD spectra were likely to superimpose on native peaks, indicating the structural stability of DNA in these concentration ranges. The CD spectra represent the structural and conformation constancy of B-DNA in the presence of PMILs within the desired concentration range for MRI application. The CD spectra of pure B-DNA and B-DNA in the presence of other PMILs are given in the ESI $\dagger$ (Fig. S5).

Fluorescence spectroscopy. The interaction of PMILs with DNA was examined by ethidium bromide (EB) exclusion assay
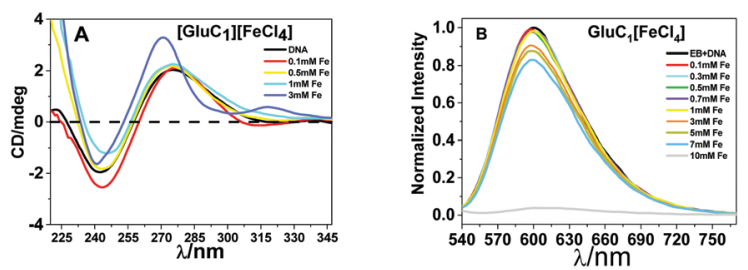

Fig. 2 (A) CD spectra and (B) fluorescence spectra of the EB-DNA complex at various $\mathrm{Fe}$ concentrations of $\mathrm{GluC}_{1}\left[\mathrm{FeCl}_{4}\right]$. 
using DNA-EB complex and fluorescence spectroscopy. EB is a well-known intercalating dye that is used as an external fluorescence probe because it intercalates into the minor grooves of DNA and enhances the fluorescence intensity 20-25 fold with respect to $\mathrm{EB}$ in pure water, with water acting as a strong quencher. $^{52}$ To achieve complete binding with DNA molecules, $25 \mathrm{~mL}$ of $1.0 \mathrm{mmol} \mathrm{L}^{-1} \mathrm{~EB}$ was mixed with the DNA solution. Fig. 2(B) shows that the PMILs do not exhibit any efficient binding to the EB-DNA complex up to $3 \mathrm{mmol} \mathrm{L}^{-1}$, and the observed spectrum resembles the native spectrum of the EB-DNA complex.

The fluorescence spectra confirmed that the tertiary structure of B-DNA was intact at a low concentration of Fe. Beyond this concentration (i.e., higher than $3 \mathrm{mmol} \mathrm{L}^{-1} \mathrm{Fe}$ ) the fluorescence intensity decreased due to the interaction of the cationic counterpart of PMILs with the minor groove of DNA via strong electrostatic interaction after complete removal of the spine of hydration. ${ }^{53}$ It can be assumed that small and more hydrated PMILs are incapable of efficiently displacing the EB due to weak interactions, and these interactions become more prominent when the concentration was increased $\left(>3 \mathrm{mmol} \mathrm{L}^{-1} \mathrm{Fe}\right)$. Less screened cations of PMILs interacted with the negative surface of DNA grooves, and consequently, EB effectively dislocated from its hydrophobic environment. ${ }^{54}$ The fluorescence spectra of DNA in the presence of other PMILs are given in the ESI, $\dagger$ (Fig. S6). These results validate the $\mathrm{CD}$ spectra results.

Isothermal titration calorimetry. To reveal the thermodynamics of DNA-PMIL binding, isothermal titration calorimetry experiments were performed. Fig. 3A shows that the change in the enthalpy $(\Delta H)$ of the DNA-PMIL interaction process is small and indicates negligible DNA-PMIL interaction at low concentrations (up to $5 \mathrm{mmol} \mathrm{L}^{-1}$ ). In the presented binding enthalpogram, the enthalpy of dilution that occurs from PMILs in buffer was subtracted using the software provided with the instrument. Above $5 \mathrm{mmol} \mathrm{L}^{-1}$ concentration, a characteristic enthalpic peak with high $\Delta \mathrm{H}$ value indicates significant DNAPMILs interactions. A similar pattern was found for all the PMILs studied here, which indicates that the PMILs have a significant impact on DNA above a certain critical concentration. Similar to the $\mathrm{CD}$ and fluorescence results, these observations show that the lower concentrations of PMILs will not harm DNA, and therefore, can be applied for MRI application. The isothermal binding of other PMILs with DNA are given in the ESI, $\dagger$ (Fig. S7).
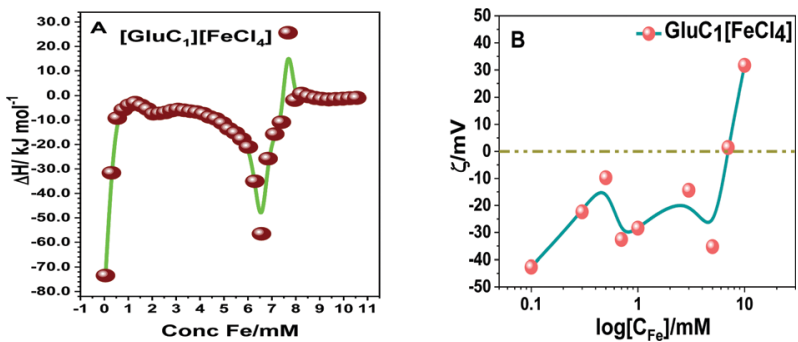

Fig. 3 (A) ITC: isothermal binding enthalpogram of $\mathrm{GluC}_{1}\left[\mathrm{FeCl}_{4}\right]$ to DNA and $(B)$ zeta potential of the DNA surface at various Fe concentrations of $\mathrm{GluC}_{1}\left[\mathrm{FeCl}_{4}\right]$.
Zeta potential. To reveal the effect of PMILs on the DNA surface, zeta potential measurements were performed. The exposed surface charge of DNA at different PMIL concentra-

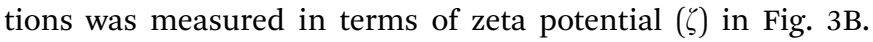
A negative value of $\zeta$ below $5 \mathrm{mmol} \mathrm{L}^{-1} \mathrm{Fe}$ concentration indicates weak interaction with DNA, and below $1.0 \mathrm{mmol} \mathrm{L}^{-1}$, DNA experiences insignificant interactions and remains stable. At higher concentrations, positive counter ions of PMILs started to interact with the exposed negative surface charge of DNA, and subsequently, the $\zeta$ value shifted to a positive value, and reached its maximum positive value of $15 \mathrm{mV}$. It is assumed that the overall exposed negative surface of DNA was neutralized through positive counter ion of PMILs. The neutralized negative surface underwent PMIL-DNA complex formation. Such a complex occurs when all negative phosphate groups bind with positive cation. ${ }^{55,56}$ This result is also in accordance with observations from the ITC enthalpogram. The zeta potentials of DNA in the presence of other PMILs are given in the ESI, $\dagger$ (Fig. S8).

Gel electrophoresis. Agarose gel electrophoresis of DNA with PMILs was used to measure DNA degradation in the presence of PMILs as a function of the Fe concentration. Gel electrophoresis results of DNA with different concentrations $(0.1,0.3,0.5$, $0.7,1,2,3$, and $5 \mathrm{mmol} \mathrm{L}^{-1} \mathrm{Fe}$ ) of PMILs after an incubation time of $6 \mathrm{~h}$ are shown in Fig. 4. Only the appearance of single bands indicates the lack of DNA degradation up to a concentration of $5 \mathrm{mmol} \mathrm{L}^{-1} \mathrm{Fe}$ of PMILs. At higher concentrations, the DNA bands disappeared due to charge neutralization or absence of unbound DNA. ${ }^{57}$ Beyond this concentration range, the bound DNA-PMIL complex did not migrate out of the wells, which most likely occurred due to size exclusion rather than charge neutralization. ${ }^{58}$

All the above results revealed that PMILs do not confer any type of negative effect on either DNA structure or its degradation. Because they have very weak or negligible interactions with DNA at the desired concentrations, diluted solutions of these PMILs can be used for biological applications such as bio imaging (MRI) application.

\subsection{In vitro MRI and relaxivity analysis in aqueous medium}

In vitro, MRI was performed under 11.7 Tesla, using a Bruker NMR spectrometer (500 MHz) with uniform capillaries. The

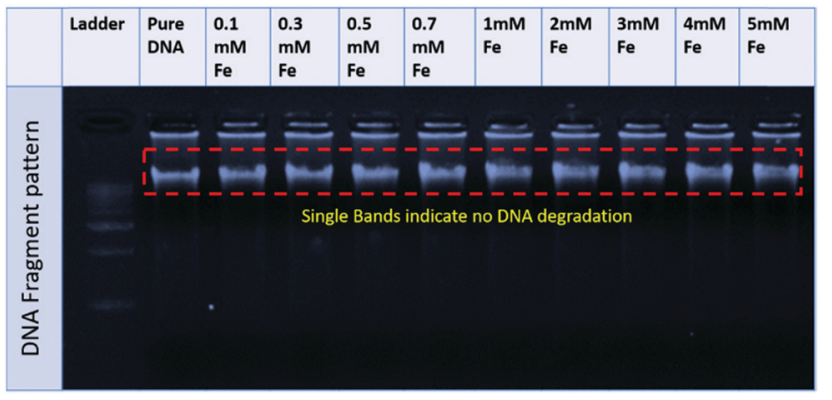

Fig. 4 Agarose gel electrophoresis pattern for a representative PMIL, $\mathrm{GluC}_{1}\left[\mathrm{FeCl}_{4}\right]$, at various $\mathrm{Fe}$ concentrations. 
longitudinal $\left(r_{1}\right)$ and transverse $\left(r_{2}\right)$ relaxivities were calculated from eqn (1), where $c$ denotes the Fe concentration of PMILs in $\mathrm{mmol} \mathrm{L}^{-1}$ :

$$
1 / T_{i, \mathrm{c}}=1 / T_{i, \mathrm{o}}+r_{i} c
$$

$T_{i, \mathrm{c}}$ denotes the relaxation time at concentration $c, T_{i 0}$ denotes the relaxation time for the solvent, and $i$ denotes 1 and 2 for $T_{1}$ and $T_{2}$, respectively. ${ }^{46} T_{1}$ and $T_{2}$ depend on various factors such as tissue type, NMR frequency, excision, age, temperature, species, and relaxation time. ${ }^{1}$ Drastic contrast enhancement in both $T_{1}$ and $T_{2}$ weighted images with the increase in PMIL concentration in phantoms reveals a qualitative capability of PMILs as $T_{1}$ and $T_{2}$ dual MRI contrast agents (Fig. 5). The $T_{1}$ and $T_{2}$ weighted images for other alanine- and valine-based PMILs are given in Fig. $\mathrm{S} 10$ (ESI $\dagger$ ). The $T_{1}$ and $T_{2}$ relaxation rates for all PMILs were found to be linearly dependent on the concentration of PMILs (measured in terms of Fe), which is consistent with previously published values. The $T_{1}$ and $T_{2}$ relaxivity values $\left(r_{1}\right.$ and $\left.r_{2}\right)$ for PMILs were found to be in the range of 6.64 to 11.06 for $r_{1}$ and 37.27 to $63.16 \mathrm{mM}^{-1} \mathrm{~s}^{-1}$ for $r_{2}$ (Table 2), which indicate that its $T_{1}$ and $T_{2}$ contrasting property is suitable for MRI diagnosis. The $r_{1}$ and $r_{2}$ relaxivities for other alanine- and valine-based PMILs are given in Fig. S11 (ESI $\dagger$ ).

The parameter $r_{2} / r_{1}$ was also measured for the investigated PMILs, and was found to be near 5 . The $r_{2} / r_{1}$ ratio is theoretically always more significant when greater than 1.0. This indicates positive contrast with $T_{1}$ mode, such as that obtained with $\mathrm{Gd}_{2} \mathrm{O}_{3}$ nanoparticles, which are a powerful $T_{1}$ MRI-positive contrast agent with $r_{2} / r_{1} \approx 1.0$ due to a higher $r_{1}$ value. However, $\mathrm{Dy}_{2} \mathrm{O}_{3}$ nanoparticles are considered to be a powerful $T_{2}$ MRI negative contrast agent with higher $r_{2} / r_{1}$ (higher $r_{2}$ value). The GDO (Gd-Dy oxide mixed) nanoparticles studied by Tegafaw et al. and hybrid lanthanide-based nanoparticles
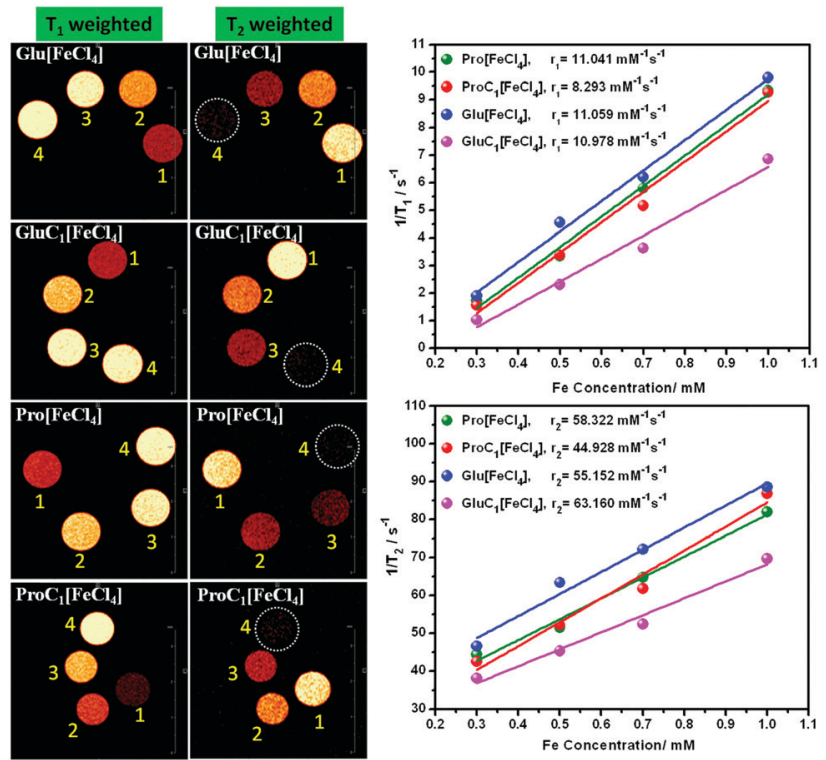

Fig. $5 T_{1}$ and $T_{2}$ weighted MR images and relaxivity of PMILs at various Fe concentrations.
Table 2 Glass transition temperature, degradation temperature, osmolality, relaxivity values $\left(r_{1}\right.$ and $\left.r_{2}\right)$, and ratio of $r_{2}$ and $r_{1}\left(r_{2} / r_{1}\right)$ for PMILs

\begin{tabular}{|c|c|c|c|c|}
\hline PMILs & $\begin{array}{l}\text { Osmolality }^{a} \\
\left(\text { Osmol kg }^{-1}\right)\end{array}$ & $r_{1}\left(\mathrm{mM}^{-1} \mathrm{~s}^{-1}\right)$ & $r_{2}\left(\mathrm{mM}^{-1} \mathrm{~s}^{-1}\right)$ & $r_{2} / r_{1}$ \\
\hline $\operatorname{Pro}\left[\mathrm{FeCl}_{4}\right]$ & 2.7 & 11.04 & 58.32 & 5.28 \\
\hline $\operatorname{ProC}_{1}\left[\mathrm{FeCl}_{4}\right]$ & 3.1 & 8.29 & 44.93 & 5.42 \\
\hline $\mathrm{Glu}\left[\mathrm{FeCl}_{4}\right]$ & 2.8 & 11.06 & 55.15 & 4.99 \\
\hline $\mathrm{GluC}_{1}\left[\mathrm{FeCl}_{4}\right]$ & 3.3 & 10.98 & 63.16 & 5.75 \\
\hline $\mathrm{Ala}\left[\mathrm{FeCl}_{4}\right]$ & 3.2 & 6.64 & 37.27 & 5.61 \\
\hline $\operatorname{Val}\left[\mathrm{FeCl}_{4}\right]$ & 3.2 & 6.81 & 38.43 & 5.64 \\
\hline Gd-BOPTA & 1.9 & 4.31 & 4.95 & 1.20 \\
\hline
\end{tabular}

${ }^{a}$ Osmolality measured at $0.5 \mathrm{M}$ Fe concentration of PMILs and $0.5 \mathrm{M}$ Gd concentration of GD-BOTA at room temperature.

investigated by Hao et al. exhibited a dual response, and the reported intermediate $r_{2} / r_{1}$ values for these nanoparticles indicated that they are suitable for use as dual-model $\left(T_{1}\right.$ and $\left.T_{2}\right)$ MRI contrast agents. ${ }^{2,7}$ Thus, our investigated PMILs can be labelled as dual responsive $\left(T_{1}\right.$ and $\left.T_{2}\right)$ contrast agents because PMILs have intermediate $r_{2} / r_{1}$ values.

\subsection{Comparison with a commercially available Gd-based contrast agent (gadobenate dimeglumine)}

In this work, we carried out a comparative study of our PMILbased MRI contrast agents with commercially available and FDA-approved Gd-based contrast agents. Here, for comparative studies, we selected gadobenate dimeglumine (Gd-BOPTA) as a model contrast agent. All experiments were carried out under same conditions, and we found that our PMIL-based contrast agents have properties comparable to those of Gd-based contrast agents, as well as significant MRI responses. From Fig. S12 (ESI $\dagger$ ), it is clear that the conformation of B-DNA is stable at $5 \mathrm{mmol} \mathrm{L}{ }^{-1}$ concentration (in terms of Gd). As can be seen from the results of various techniques employed for PMILs and after comparison with GD-BOPTA, the PMILs can be used as contrast agents in MRI diagnosis within a broad concentration range where DNA does not lose its structural and conformational stability and remains intact as native B-DNA. The relaxivity values $\left(r_{1}\right.$ and $\left.r_{2}\right)$ for Gd-BOTPA are significantly too small compared to PMILs, and the ratio of $r_{2} / r_{1}$ for Gd-BOTPA is approximately 1.2 , which indicates that it can be used only as a positive contrast agent ( $T_{1}$ mode) (Fig. 6).

The osmolarity values for the PMILs are the total number of constituents of any species present in their solution by weight. The values were found to be in the range of $3 \mathrm{Osmol} \mathrm{kg}^{-1}$ for the investigated PMILs, which are comparable to the Gd-BOTA contrast agent. Low osmolality assists with reducing pain and other contrary effects during injection. ${ }^{59}$ The osmolality value of PMILs are given in Table 2.

\subsection{Advantages of the investigated PMILs}

Amino acid-based PMILs have several advantages over Gdbased or other available contrast agents. For example, Gwinn et al. reviewed the pros and cons of nanoparticle-based MRI contrast agents regarding health and concluded that the toxic effect of these nanoparticles is similar to that which results 

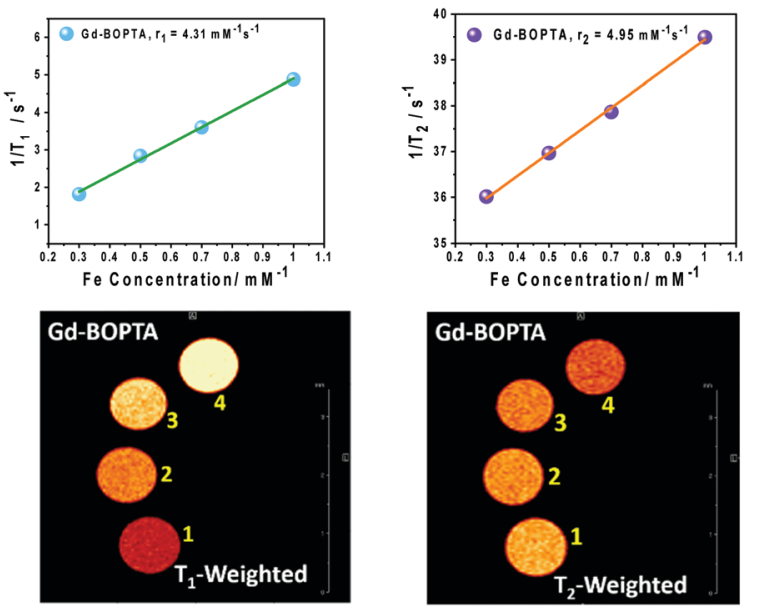

Fig. $6 T_{1}$ and $T_{2}$ weighted MR images and relaxivity $\left(r_{1}\right.$ and $\left.r_{2}\right)$ of GdBOPTA at various $\mathrm{Gd}$ concentrations.

from exposure to airborne ultra-fine particles (UFPs), which causes diseases with long latency. ${ }^{5}$

Tang et al. recently reviewed the various adverse effects of NPs on cell organelles, and reported that NPs cause mitochondrial dysfunction, endoplasmic reticulum stress, and lysosomal rupture. ${ }^{60}$ Gd-based contrast agents (GBCAs) used for MRI also adversely affect health. A report from an FDA drug safety newsletter has criticized GBCAs because of the drastic effect of Gd on health, and their detrimental effect upon the kidneys, such as fibrosing disease, NSF (nephrogenic systemic fibrosis) with acute or chronic severe renal (kidney) insufficiency, and renal dysfunction. Researchers have found accumulated gadolinium in the renal tissue of patients who developed NSF after the administration of GBCAs. ${ }^{40}$ The investigated PMILs in this manuscript have the following advantages:

(1) The synthesis process is simple, less time consuming, and cost-effective. Synthesis is carried out in an ethanol solvent medium to overcome the detrimental effect of methanol.

(2) Like metal-ligand-based MRI contrast agents, there is no requirement of a tedious pre-synthesis of ligands, costly precursors, reactants, toxic reagents, or volatile organic solvents for synthesis. Thus, such MRI contrast agents will be inexpensive products and can be prepared according to the principles of green synthesis.

(3) The problems regarding thermodynamic instability of the ligand-metal complexes are unlikely to occur with PMILs. Thus, metal leaching will not occur.

(4) The use of Fe metal in ionic liquids excludes the severe health problems and adverse effects that result from the use of toxic metals such as Gd.

\section{Conclusions}

Novel amino acid-based paramagnetic ionic liquids (PMILs) were synthesized via two methods: (1) without esterification and (2) with methyl esterification. The suitability of these PMILs to act as contrast agents in MRI applications was examined by studying their interactions with DNA, and determining if any alteration of structure or instability occurred in the DNA. The results indicated that DNA was stable and maintained its structural constancy up to a $3 \mathrm{mmol} \mathrm{L}{ }^{-1}$ PMIL concentration (in terms of $\mathrm{Fe}$ ).

Solutions from 0.1 to $1 \mathrm{mmol} \mathrm{L}^{-1}$ concentration underwent in vitro $\mathrm{MRI}$ analysis. $T_{1}$-weighted and $T_{2}$-weighted image analysis confirmed their dual-mode behaviour as contrast agents. Comparisons of relaxivity and other physical properties of synthesized PMILs with those of commercially available Gd-based MRI contrast agents showed that PMILS are prominent contrast agents that can be used for MRI applications. Hence, further investigations such as in vivo MRI analysis are being conducted. Synthesized PMILs are appropriate for use as potential dual contrast agents for MRI, and further studies can be carried out to explore their real-time applications in medical science.

\section{Conflicts of interest}

There are no conflicts to declare.

\section{Acknowledgements}

PRIS number CSIR-CSMCRI-47/2020. Financial support through a Senior Research Fellowship to P. S. G. from the University Grant Commission (UGC, Govt. of India) is also acknowledged here. The Department of Science and Technology (DST), India is acknowledged for financial support (No. EMR/2016/004747). The authors acknowledge the central instrumentation facility of CSIR-CSMCRI for assisting with sample characterization.

\section{References}

1 P. A. Bottomley, T. H. Foster, R. E. Argersinger and L. M. Pfeifer, Med. Phys., 1984, 11, 425-448.

2 T. Tegafaw, W. Xu, M. W. Ahmad, J. S. Baeck, Y. Chang, J. E. Bae, K. S. Chae, T. J. Kim and G. H. Lee, Nanotechnology, 2015, 26, 365102.

3 Y. Xiao and J. Du, J. Mater. Chem. B, 2020, 8, 354-367.

4 C. Tapeinos, M. Battaglini, A. Marino and G. Ciofani, J. Mater. Chem. B, 2020, 8, 6233-6251.

5 M. R. Gwinn and V. Vallyathan, Environ. Health Perspect., 2006, 1818-1825.

6 T.-H. Shin, J.-s. Choi, S. Yun, I.-S. Kim, H.-T. Song, Y. Kim, K. I. Park and J. Cheon, ACS Nano, 2014, 8, 3393-3401.

7 Z. Yi, X. Li, W. Lu, H. Liu, S. Zeng and J. Hao, J. Mater. Chem. $B, 2016,4,2715-2722$.

8 T. Hyeon, K. Na, D. Ling and W. Park, US Pat., 20160089455A1, 2016.

9 H. Satoshi and H. Hiro-o, Chem. Lett., 2004, 33, 1590-1591.

10 H. V. Ersoz, US Pat., 20130314080A1, 2013.

11 G. M. Whitesides, A. Ellerbee and S. Tricard, US Pat., 13989725, 2016.

12 T. Yao, S. Yao, C. Pan, X. Dai and H. Song, Energy Fuels, 2016, 30, 4740-4749.

13 F. Shi, J. Peng and Y. Deng, J. Catal., 2003, 219, 372-375. 
14 T. Chatzimitakos, C. Binellas, K. Maidatsi and C. Stalikas, Anal. Chim. Acta, 2016, 910, 53-59.

15 M. J. Trujillo-Rodríguez, O. Nacham, K. D. Clark, V. Pino, J. L. Anderson, J. H. Ayala and A. M. Afonso, Anal. Chim. Acta, 2016, 934, 106-113.

16 J. Merib, D. A. Spudeit, G. Corazza, E. Carasek and J. L. Anderson, Anal. Bioanal. Chem., 2018, 410, 4689-4699.

17 K. F. Wang, L. Zhang, R. R. Zhuang and F. F. Jian, Transition Met. Chem., 2011, 36, 785-791.

18 S. Kim, C. Bellouard, J. Eastoe, N. Canilho, S. E. Rogers, D. Ihiawakrim, O. Ersen and A. Pasc, J. Am. Chem. Soc., 2016, 138, 2552-2555.

19 A. Klee, S. Prevost and M. Gradzielski, ChemPhysChem, 2014, 15, 4032-4041.

20 A. Khalafi-Nezhad and S. Mohammadi, ACS Comb. Sci., 2013, 15, 512-518.

21 D. K. Bwambok, M. M. Thuo, M. B. Atkinson, K. A. Mirica, N. D. Shapiro and G. M. Whitesides, Anal. Chem., 2013, 85, 8442-8447.

22 J. Thévenot, H. Oliveira, O. Sandre and S. Lecommandoux, Chem. Soc. Rev., 2013, 42, 7099-7116.

23 M. Döbbelin, V. Jovanovski, I. Llarena, L. J. C. Marfil, G. Cabañero, J. Rodriguez and D. Mecerreyes, Polym. Chem., 2011, 2, 1275-1278.

24 A. Klee, S. Prevost, W. Kunz, R. Schweins, K. Kiefer and M. Gradzielski, Phys. Chem. Chem. Phys., 2012, 14, 15355-15360.

25 A. Khalafi-Nezhad and S. Mohammadi, RSC Adv., 2014, 4, 13782-13787.

26 E. Santos, J. Albo, A. Rosatella, C. A. Afonso and Á. Irabien, J. Chem. Technol. Biotechnol., 2014, 89, 866-871.

27 K. D. Clark, O. Nacham, J. A. Purslow, S. A. Pierson and J. L. Anderson, Anal. Chim. Acta, 2016, 934, 9-21.

28 J. L. Anderson and K. D. Clark, Anal. Bioanal. Chem., 2018, 410, 4565-4566.

29 A. Joseph, G. Żyła, V. I. Thomas, P. R. Nair, A. Padmanabhan and S. Mathew, J. Mol. Liq., 2016, 218, 319-331.

30 A. Kulshrestha, G. Kumar, N. H. Khan and A. Kumar, J. Mol. Liq., 2019, 112157, DOI: 10.1016/j.molliq.2019.112157.

31 M. Konwar, H. M. F. Elnagdy, P. S. Gehlot, N. D. Khupse, A. Kumar and D. Sarma, J. Chem. Sci., 2019, 131, 80.

32 P. Brown, A. Bushmelev, C. P. Butts, J. Cheng, J. Eastoe, I. Grillo, R. K. Heenan and A. M. Schmidt, Angew. Chem., Int. Ed., 2012, 51, 2414-2416.

33 K. D. Clark, M. Sorensen, O. Nacham and J. L. Anderson, RSC Adv., 2016, 6, 39846-39851.

34 K. D. Clark, O. Nacham, H. Yu, T. Li, M. M. Yamsek, D. R. Ronning and J. L. Anderson, Anal. Chem., 2015, 87, 1552-1559.

35 A. Kulshrestha, P. S. Gehlot and A. Kumar, J. Mater. Chem. B, 2020, 8, 3050-3057.

36 C. I. Daniel, F. N. Vaca Chávez, C. A. Portugal, J. G. Crespo and P. J. Sebastiao, J. Phys. Chem. B, 2015, 119, 11740-11747.
37 P. S. Gehlot, H. Gupta and A. Kumar, Colloid Interface Sci. Commun., 2018, 26, 14-23.

38 A. Kumar, H. Gupta, P. Singh Gehlot and S. Mangal Rathore, Indian Pat., IN201711043528, 2019.

39 S. Ye, Y. Liu, Y. Lu, Y. Ji, L. Mei, M. Yang, X. Gong, Q. Gu, D. Li, F. Yang and C.-J. Li, J. Mater. Chem. B, 2020, 8, 447-453.

40 W. A. High, R. A. Ayers, J. Chandler, G. Zito and S. E. Cowper, J. Am. Acad. Dermatol., 2007, 56, 21-26.

41 M. Agarwal, M. Murugan, A. Sharma, R. Rai, A. Kamboj, H. Sharma and S. K. Roy, Int. J. Curr. Microbiol. Appl. Sci., 2013, 2, 39.

42 N. Hoshyar, S. Gray, H. Han and G. Bao, Nanomedicine, 2016, 11, 673-692.

43 J. Li and Y. Sha, Molecules, 2008, 13, 1111-1119.

44 M. Li, S. L. De Rooy, D. K. Bwambok, B. El-Zahab, J. F. DiTusa and I. M. Warner, Chem. Commun., 2009, 6922-6924.

45 A. Bhadani and S. Singh, Langmuir, 2011, 27, 14033-14044. 46 H. Gupta, P. Paul, N. Kumar, S. Baxi and D. P. Das, J. Colloid Interface Sci., 2014, 430, 221-228.

47 T. Bäcker, O. Breunig, M. Valldor, K. Merz, V. Vasylyeva and A.-V. Mudring, Cryst. Growth Des., 2011, 11, 2564-2571.

48 M. S. Sitze, E. R. Schreiter, E. V. Patterson and R. G. Freeman, Inorg. Chem., 2001, 40, 2298-2304.

49 W. Dariusz, S. Artur, K. Julia, M. Jerzy, S. Emilia and W. Zygmund, Z. Anorg. Allg. Chem., 2009, 635, 1249-1253.

50 C. P. Fredlake, J. M. Crosthwaite, D. G. Hert, S. N. Aki and J. F. Brennecke, J. Chem. Eng. Data, 2004, 49, 954-964.

51 Y.-M. Chang, C. K.-M. Chen and M.-H. Hou, Int. J. Mol. Sci., 2012, 13, 3394-3413.

52 J.-B. Le Pecq and C. Paoletti, Anal. Biochem., 1966, 17, 100-107.

53 A. Chandran, D. Ghoshdastidar and S. Senapati, J. Am. Chem. Soc., 2012, 134, 20330-20339.

54 S. Satpathi, A. Sengupta, V. Hridya, K. Gavvala, R. K. Koninti, B. Roy and P. Hazra, Sci. Rep., 2015, 5, 9137.

55 K. Rawat, J. Pathak and H. Bohidar, Phys. Chem. Chem. Phys., 2013, 15, 12262-12273.

56 S. Hou, N. Ziebacz, S. A. Wieczorek, E. Kalwarczyk, V. Sashuk, T. Kalwarczyk, T. S. Kaminski and R. Holyst, Soft Matter, 2011, 7, 6967-6972.

57 Z. Ziraksaz, A. Nomani, M. Ruponen, M. Soleimani, M. Tabbakhian and I. Haririan, Eur. J. Pharm. Sci., 2013, 48, 55-63.

58 S. Eastman, C. Siegel, J. Tousignant, A. Smith, S. Cheng and R. Scheule, Biochim. Biophys. Acta, Biomembr., 1997, 1325, 41-62.

59 J. A. Peters and K. Djanashvili, Reference Module in Materials Science and Materials Engineering, Elsevier, 2016, DOI: 10.1016/B978-0-12-803581-8.01826-9.

60 N. Liu and M. Tang, J. Appl. Toxicol., 2020, 40, 16-36. 